spleen. The gall-bladder and bile ducts were normal. The stomach appeared normal but contained grumous bloodstained fluid, as did the upper four yards of the intestine. In the lower part of the jejunum a superficial ulcer was found involving a valvula connivens, and extending transversely for an inch, and from this hæmorrhage had been recent. The pancreas and suprarenals were normal. The kidneys (left, 17 ounces; right, 16 ounces) were large and the surface was waxy in appearance, the capsules stripping easily. On section the organs, except at the centre of the pyramids, were of the colour of yellow fat. Iodine showed lardaceous degeneration. The liver did not give this reaction. The spleen (8 ounces) was waxy and contained three infarcts. To the naked eye the left testis was fibroid, the right normal. The case was therefore one of lardaceous disease following syphilis, complicated by hæmorrhage, presumably from the kidney, and terminally from the bowel, with patches of old perihepatitis deforming the liver.

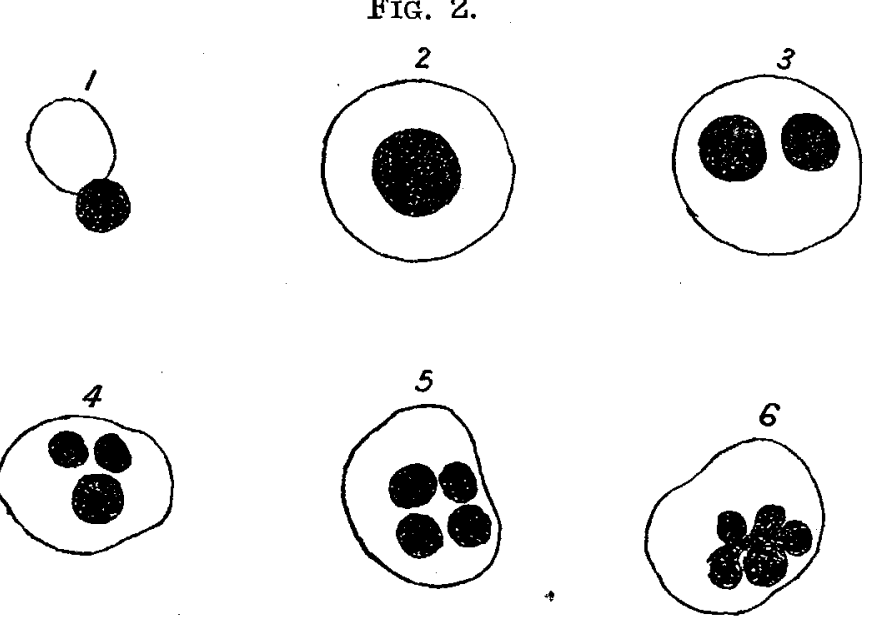

Selected cells to show (1) escaping nucleus, (2) single nucleated red cell, (3) double nucleated red cell, and (4), (5), and (6) polynucleated red cells.

Several points of interest may be mentioned. The most prominent feature after the abdominal symptoms had subsided was pronounced anæmia following the hæmorrhage from the kidneys. It is probable, however, that there was a considerable amount of anæmia antecedent to the hæmorrhage, in which case even a moderate loss of blood would be sufficient to account for the occurrence of blood crisis.

Blood crisis is not uncommon in some forms of anæmia and is not infrequently met with in the apyrexial stage following pernicious malarial attacks, but a case so pronounced as that under review, associated as it proved to be with amyloid disease of the kidney, is seldom seen and should be placed on record. The points worthy of notice are: 1. The enormous number of nucleated red cells-on April 26 th over 20,000 per cubic millimetre. 2. The rapid increase in number of the red cells from 1,100,000 per cubic millimetre on April 26th to $3,950,000$ on May 17th, and in the amount of hæmoglobin from 29 to 58 per cent. ; and the improvement in the patient's general condition following the blood crisis which may be regarded as of the nature of a regenerative process. 3. The remarkable rapidity with which the nucleated cells disappeared; on May 2nd, eight days after the crisis, there was not one to be seen.

Bleeding from the kidneys is an uncommon symptom in lardaceous disease. Dickinson says in Allbutt's "System of Medicine" that in the urine of lardaceous kidneys blood is but rarely present, but that when present it is sometimes in considerable quantity (Vol. IV.). In the same article he says that hæmorrhagic complications are rare, epistaxis being the most common. In this case bleeding took place before death from a superficial ulcer in the jejunum. A similar occurrence is recorded by Steinhaus. ${ }^{1}$ Thrombosis, again, is not a common complication. It was found by Dickinson twice in 74 cases. The one typical symptom of lardaceous disease of the kidney which was present was diarrhoea. Edema did not occur except in connexion with venous thrombosis.

It is difficult to determine whether the patches of capsular fibrosis deforming the liver are to be attributed to syphilis

I Schmidt's Jahrbericht der Medicin, vol. celxxvii., p. 40, 1903 or to acute perihepatitis accompanying the attacks of congestion of the liver from which the patient had suffered. On account of the circumscribed nature of the patches we are inclined to regard the condition as a syphilitic one.

\section{THE TREATMENT OF EMPYEMATA WITH NOTES FROM 55 CONSECUTIVE CASES.} BY GEORGE E. WAUGH, B.A. CANTAB., M.D., B.S.
LOND., F.R.C.S. ENG.,

SURGEON TO OUT-PATIENTS, HOSPITAI FOR SICK CHILDREN, GREAT ORMOND-STREET.

As the question of the relative merits of the treatment of empyemata by resection of ribs or by intercostal incision without resection of ribs is still an occasional subject of discussion, especially amongst those who favour the latter mode of procedure, it may be of interest to place on record an analysis of the following 55 consecutive cases which were treated by the former method. The theoretical justification of this method lies in the fact that by these means only can the proper surgical principles which govern the treatment of abscesses be applied. The urgent need for the application of these principles would perhaps be more obvious if the condition was always referred to as an "interpleural abscess" rather than by the less suggestive title "empyema." These principles are briefly the establishment of a drainage of the infected area that shall allow of the most rapid escape of infected material from it combined with the removal of the maximum amount of septic material at the time of operation. An incision, which extends for the whole length of the greatest diameter of the infected area, satisfies these requirements and should only be abandoned when anatomical limitations prevent its completion. In such a way only may the conversion of an acute into a chronic abscess be avoided, with all the accompanying disadvantages of prolonged impairment of health, increased destruction of tissues, subsequent deformity, and even loss of life. Unfortunately, in the case of empyemata a compromise has to be effected, and the further that compromise is from the principles indicated the more frequent will be the occurrence of those disastrous forms of chronic empyema which terminate miserably in amyloid disease, general septic infection of other serous cavities, or eren survival after the performance of an Estlander's operation.

Delay in the application of appropriate treatment is an additional factor tending towards failure. Such delay is, as a rule, the result of failure to recognise the presence of pus in the pleural cavity. The differentiation of this condition from one of extensive consolidation of the lung may be of considerable difficulty. In a certain number of these cases sent to the hospital this reason for perferring the latter diagnosis-viz., "that there was no displacement of viscera"-was frequently given, and had unfortunately led to considerable delay in the application of proper treatment. But the mechanical conditions obtaining within the thorax are not favourable either to the displacement of the heart or to the depression of the liver or spleen by a pleural effusion. The thrust of the fluid ought either to act directly on the viscera or to be transmitted to them through a rigid substance. In most instances the lung intervenes between the effusion and any other viscus and collapses - or condensesto make room within the thoracic cavity for the effusion. The whole thrust of the fluid is thus used up in maintaining the lung in a collapsed condition and not until the lung is incapable of yielding to any further extent can the thrusting effect of the fluid be transmitted to adjacent viscera.

Evidence of displacement of viscera was carefully sought for in 41 consecutive cases. In only 19 was it found and in many of these cases a slight enlargement in the area of cardiac dulness or the fact that the lower edge of the liver and spleen was palpable was accepted as such evidence, so as to avoid the error of unduly minimising the apparent frequency of the occurrence of displacement. In many cases in which the effusion was large - in one case 35 ounces were withdrawn from a child seven years old-no signs of displacement could be found, whilst such signs were present in other cases from which only three or four ounces of fluid were removed. The conclusion to be drawn is that so-called signs of displacement of viscera are in many cases merely 
signs of enlargement of viscera, and that the absence of these signs is of little value in excluding the presence of fluid in the chest.

Technique of operation. - In all 55 cases from two to three inches of rib were removed so as to admit a drainagetube of about three-quarters of an inch in diameter. To do this in some cases it was necessary to remove portions of two ribs. The centre of the incision was made to coincide with the point through which pus had been drawn by the exploring needle. To take the lowest point of the dull area for the site of operation is to run a risk of opening the pleural cavity below the empyema, since the dulness may be due to thickened pleura or collapsed lung, and in some instances the lower part of the diaphragm may be adherent to the wall of the thorax and if not recognised the abdominal cavity may be opened. Nor is there any advantage for subsequent drainage in choosing the lowest point, since during the time when drainage is most active after the operation the patient is nearly always in the recumbent position. Consequently the posterior thoracic wall becomes the floor of the empyema and this will drain quite freely through any hole in its floor so long as the patient is lying down. By the time that a different posture can be assumed the need for very free drainage has passed.

Having allowed the contents of the abscess to escape slowly the "toilet of the pleura" was then performed with the same care that is devoted to the "toilet of the peritoneum." If the pus was thin and the cavity was not lined by lymph the whole of the wall of empyema was sponged with sterilised gauze mops soaked in saline solution and then with dry gauze mops. But if the empyema was of such long standing that the surface of the lung and the inner wall of the thorax were covered by thick lymph then both the visceral and parietal layers of pleura forming the boundaries of the cavity were systematically scraped with a sharp spoon so as to detach the whole of the layer of lymph. The cavity was then cleaned by gauze mops as before. By this method the maximum amount of septic matter is removed at the time of operation and subsequent interference with drainage by solid particles of lymph is prevented. If the cavity was bounded by adhesions that yielded easily to pressure they were broken down, since they frequently intervened between other collections of pus and the main cavity. Tough adhesions, on the other hand, that offered considerable resistance were not broken down, since they form, as a rule, the extreme limits of the abscess cavity. On completion of the operation a rubber drainage-tube, the length of which only just exceeded the thickness of the wall of the thorax, was inserted. short tube with a wide lumen, such as that specially designed for this type of case by Bilton Pollard, combines the essentials for rapid and free drainage without acting as a foreign body inside the abscess cavity. No antiseptics were nsed during the course of the operation and no finger was introduced into the wound. This is of the utmost importance. The limits of the abscess cavity can be thoroughly explored and the strength of the adhesions satisfactorily tested by any sterilised blunt instrument. Further, all mops, tubes, and dressings that came into immediate contact with the wound or abscess cavity were applied by means of large sterilised forceps, and this procedure was rigidly adhered to in all the subsequent dressings.

After-treatment.-Attempts were made to dispense with the use of the rubber drainage tube within 48 hours after the operation. In most cases, however, it was necessary to retain it for five or six days. A small wick of sterilised plain gauze was then substituted for it and shortened daily. The patients' beds were drawn up alongside windows which were kept widely open at the bottom day and night. Their heads and hands were kept warm by means of a woollen cap and gloves. The wound was dressed daily under the strict aseptic conditions already referred to. The patients were allowed to get up as soon as their general strength permitted. No "pulmonary gymnastics" (the term is borrowed) were indulged in. The failure of the lung to expand is not from any increased pressure on the outer surface of the lung (the pressure is rather decreased by the operation since a dense fluid "pus" is replaced by a rarer fluid "air"), but because a part of the lung is forming part of the wall of the abscess cavity and is consequently infiltrated with inflammatory exudation. The more rapidly these products are drained away the more rapidly will expansibility of the lung return and to attempt to restore this by inflating the lung by the use of Wollf's bottles is a confession that drainage of the abscess cavity has either been applied too late or that it is inadequate. If free drainage is established early in the course of the illness the expansibility of the lung is only temporarily impaired and returns pari passu with the healing of the rest of the wall of the abscess cavity. In cases of long standing where drainage has been established late or where inadequate drainage was established at the time of operation permanent fibrotic changes have occurred in the lung tissue forming the wall of the abscess cavity and no hyperpnœa will ever convert that fibrous tissue again into lung tissue. Another tissue whose powers of recuperation may be

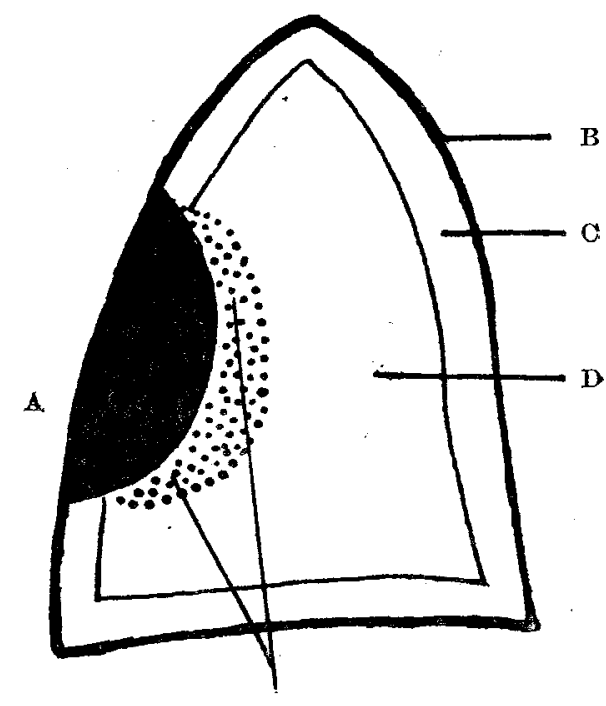

Diagram showing the area of the lung in which expansile power is impaired either temporarily or permanently. A, Empyema. B, Wall of thorax. C, Pleural cavity. D, Lung. E, Area of " condensed" or "collapsed" lung forming the wall of the empyema.

permanently destroyed as the result of prolonged inadequate drainage is the periosteum stripped off the ribs at the time of operation. With free rapid drainage its osteogenetic powers are not impaired and consequently the gap made in the bony framework of the thorax is filled up by new bone within about eight weeks from the date of operation.

Results. - 11 cases out of the 55 died. Only one of the fatal cases was a simple uncomplicated empyema. Included in the 55 consecutive cases of empyema are several cases in which pus in the pleural cavity was only an incident of a general disease. Thus two of the fatal cases were almost moribund at the time of admission to hospital and died within 24 hours after the operation. Post mortem the meninges, pericardium, and peritoneum were found also to be covered by a purulent exudate. Five other fatal cases had been suffering from abdominal and pulmonary tuberculosis for some months before the development of an empyema. They eventually died from general tuberculosis some weeks later but in spite of the general illness the empyemata were healing quite satisfactorily. In two other fatal cases the empyemata were only secondary to abscesses in the lungs of some months' duration before the time of operation. One case developed broncho-pneumonia a month after the date of operation and died. The one case of simple uncomplicated empyema which ended fatally has a clinical course of particular interest in view of the treatment applied to subsequent cases of the same type which ended in recovery. Briefly, the child lived for three weeks from the date of operation, but although the abscess cavity became quite clean and only a thin serum was discbarged daily no attempt at repair occurred and the child became progressively weaker and died from no detectable cause. Post mortem a large clean cavity was found in the pleura and the lung was collapsed; otherwise the child was healthy. Such cases of progressive asthenia ending fatally after an operation for empyema in which no morbid condition can be found post mortem sufficient to account for death are not uncommon. The chief characteristics of such cases are a progressive improvement in the local condition accompanied by a progressive impairment in the general condition of the patient, and neither before nor after death is the cause of the fatal termination evident. In three 
cases exhibiting such features after the first operation active treatment was resorted to and the immediate change in the general condition of the patients was so striking as to encourage the belief that probably such a line of treatment had averted a fatal issue. In all these cases after an anæsthetic had been given again the surface wound was excised, the interpleural cavity was well sprayed out with hot saline solution, then dried by means of sterilised gauze mops, and finally the opening in the chest wall was entirely closed by stitches. In all cases healing occurred by first intention and the children made uninterrupted recoveries. The following notes give a brief account of one of these cases.

A child, aged 18 months, who had suffered from whoopingcough for the five weeks immediately preceding the date of operation, was admitted to the hospital on Dec. 6th with signs of a right-sided empyema. A rib was resected on that date and the usual routine treatment applied. On the 13th an empyema was detected on the left side and similar treatment adopted. Both cavities became quite clean as the result of drainage but showed no signs of filling up. The patient became profoundly emaciated and on Jan. 1st of the following year was in a marasmic condition and able to take only a slight amount of liquid nourishment. His weight was only 19 pounds. No cause for this general and progressive asthenia could be discovered. Chloroform was administered, the cavities in the interpleural space were cleaned, and the wounds excised and closed as already described. Immediate improvement followed. Both wounds healed by first intention. By the end of a week the child had gained one pound in weight and on Feb. 27th he was discharged as quite well, having gained four pounds in weight since the date of the second operation. Six months later he was seen and was a well-nourished healthy child having had no further trouble. The histories of the other two cases are very similar except that each patient only suffered from a single empyema. It is as difficuit to give an explanation of the recovery in such cases as it is of the death of the other referred to above. The result of the method of treatment adopted, however, is encouraging and appears to be worthy of further trial. Of the remaining 44 cases which recovered one had a double empyema and was not completely healed until 73 days from the date of the first operation, the convalescence being interrupted by an attack of broncho-pneumonia. Six cases took 41 days to heal; six cases took 30 days to heal; seven cases took from 21 to 28 days to heal ; 15 cases were healed in less than 21 days; whilst nine cases were healed within 14 days from the date of operation. (By " healed" is implied that the wound was entirely covered by skin and that the patient in other respects was quite well.)

I must express my indebtedness to my colleagues at Great Ormond-street for placing so much clinical material at my disposal during my tenure of the post of resident medical superintendent and for their permission to make use of the notes on the cases.

Welbeck-street, $\mathrm{w}$.

\section{SINGLE AND SUCCESSIVE EXTRA-} SYSTOLES.

\section{By THOMAS LEWIS, M.D. LoND., D.So. Wales,} M.R.C.P. LOND.,

ASSISTANT PHYSICIAN TO THE SEAMEN'S HOSPITAL, GREENWICH; AND PHYSICIAN TO OUI-PATIENTS, CITY OF LONDON HOSPITAX.

THE patient, a seaman, was first seen in the out-patients' department of the Seamen's Hospital Society, Greenwich, in August, 1908. The following details of his history and state may be placed on record. The family history contained nothing relevant. He stated that he had suffered from "gout" 12 years previously and that at that time he had had swelling of his great toes with considerable pain and tenderness. He also said that he had had one or two mild. attacks since. About 12 years ago he had "infuenza" which laid him up for some weeks. Otherwise his health had been good. Venereal disease was denied; and there was no statement of value which might incline one to the view that he had ever suffered from rheumatic infection. His present trouble began in July, 1906, when a heavy case fell on his leg and he was laid up in an infirmary for six weeks. He stated that he had since suffered, from time to time, from pain or uneasiness in the chest and that he had been short of breath on exertion.

The patient was admitted as an in-patient at the Seamen's Hospital on August 27th, 1906, complaining of pain in the limbs and shortness of breath. The notes taken at this time show that the chest moved well and that there were no abnormal physical signs on percussion or auscultation of the lungs. The cardiac dulness is described as " not increased." There were no murmurs. The pulse was markedly irregular. The abdomen was full and the liver was palpable. He was discharged on Sept. 30th. In the interval he had several attacks of shortness of breath, some of which were nocturnal. On one occasion a systolic murmur was noted at the apex. The pulse-rate is recorded as $44,48,50,52,48,60,72$, and 96 , the last figures being given shortly before the date of discharge, when the pulse is said to have been regular. The respiratory rates are given as $28,20,24,20,16,18,29$, \&c. The temperature was normal throughout.

On Nov. 19th, 1906, he was readmitted, with shortness of breath, præcordial pain, and slight dropsy. He had a slight cough and sputum. The pulse was described as small and irregular. The heart's limits were found in the nipple line in the fifth and sixth spaces, at the left edge of the sternum and at the fourth rib. The sounds were irregular and of triple rhythm, but no murmurs were heard. Crepitations at the bases and enlarged and tender liver are described. The spleen was not felt. The arteries were somewhat tortuous and thickened. The temperature was normal throughout; the pulse was counted at rates varying from 50 to 96 . There was $\frac{1}{2}$ per 1000 of albumin in the urine upon admission, the specific gravity being 1005 . The quantity varied during his stay from 14 to 47 ounces. The albumin had practically disappeared when he was discharged "much improved" on Jan. 30th, 1907.

The patient has been attending the out-patients' department off and on ever since, and the notes show in the main that his state has been the same throughout. Shortness of breath on exertion, a certain degree of præcordial uneasiness, and palpitation have been present. His cough has at times been troublesome. The pulse has varied but has usually been wildly irregular. There are no notes of any appreciable degree of cardiac dilatation. His condition when first seen by the writer, and ever since, has been the same. When he rests he is better and his chief troubles are the skortness of breath and palpitation brought on by exertion and the strain of a now almost constant cough. He has never shown cardiac dilatation while under obsservation, neither have there been any murmurs, except on one occasion, when he came with slight dropsy of the lower limbs, the apex beat at the nipple line (four inches from the left border of the sternum), and a short systolic bruit. The veins of the neck are always more prominent than they should be and pulsate markedly with the patient standing. The pulse irregularity has always been the chief feature of the case and his general condition varies with the degree of irregularity present. The heartsounds correspond to the pulse - that is to say, there is a normal first and second sound $w$ ith each beat transmitted to the wrist, and a first sound only upon the occasions when the beat fails to reach the periphery. The sounds at the apex and epigastrium have always shown correspondence; the first and second sounds have never been observed to reduplicate. He is at times capable of considerable exertion and usually walks a mile to the out-patients' department. ${ }^{1}$

Numerous records of the irregularities have been taken and some of these are published as illustrative of the cardiac movements. It is obvious that the low pulse counts made during his stays in hospital were due to weak or missed beats. In brief, there are rare occasions on which the pulse is regular and it then varies between 100 and 120 . Usually the beats are coupled or there is marked irregularity. Simultaneous radial and venous curves have allowed analysis of most of the irregularities and the observations have been checked and amplified by electro-cardiograms taken at Professor A. Waller's laboratory at South Kensington.

The first tracing (Fig. 1) shows two phases. In the first portion of the curve are five normal beats, each followed by an extra-systole at a definite and fixed time interval. Suddenly the pulse rhythm alters and each beat is

1 Since this article was written the man has been an in-patient. The irregular pulse still constitutes the most important physical sign. 